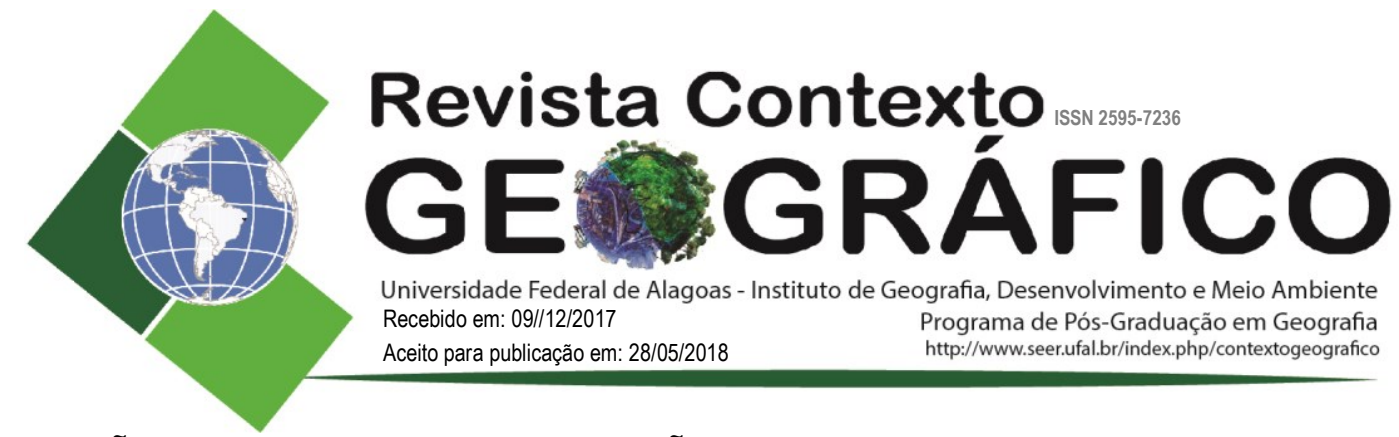

\title{
SEÇÕES-TIPO E REPRESENTAÇÃO INTEGRADA DAS PAISAGENS NO ESTADO DE SERGIPE
}

\author{
Riclaudio Silva Santos \\ Universidade Federal de Sergipe, Campus Itabaiana, SE, Brasil \\ riclaudio.silva@hotmail.com \\ Daniel Rodrigues de Lira \\ Universidade Federal de Sergipe, Campus Itabaiana, SE, Brasil \\ dniellira@gmail.com \\ Cristiano Aprígio dos Santos \\ Universidade Federal de Sergipe, Campus Itabaiana, SE, Brasil \\ aprigeo@gmail.com
}

\begin{abstract}
RESUMO - O presente estudo teve como objetivo construir perfis integrados das paisagens (Seções-Tipo), em diferentes áreas do estado de Sergipe, visando abranger o contexto geomorfológico deste estado. Por meio do Sensoriamento Remoto e do Geoprocessamento. Foram utilizados bancos de dados, além de pesquisas anteriores, para elaborar os perfis que apresentam as características litológicas, pedológicas, geomorfológicas, da topografia e da cobertura vegetal dos diferentes contextos geomorfológicos. A partir da construção dos referidos perfis, foi possível observar as características principais das áreas em estudo, assim como entender a estrutura que reúne os componentes destas paisagens. Para realizar um comparativo entre os perfis, levando-se em conta seus diferentes contextos geomorfológicos e as características identificadas nas diferentes paisagens.
\end{abstract}

Palavras-chave: Geomorfologia; Geossistemas; Modelagem Espacial.

\section{REPRESENTATION AND SECTIONS-TYPE INTEGRATED OF LANDSCAPES IN THE STATE OF SERGIPE}

\begin{abstract}
The present study aimed to construct three integrated landscapes profiles, in different areas of the state of Sergipe, aiming to cover the geomorphological context of this state. Through the Remote Sensing and Geoprocessing, databases were use, as well as previous researches, to elaborate the profiles that present the lithological, pedological, geomorphological, topography and vegetation cover profiles of different geomorphological contexts. From the construction of these profiles, it was possible to observe the main characteristics of the areas under study, as well as to understand the structure that brings together the components of these landscapes. To make a comparison between the profiles, taking into account their different geomorphological contexts and the characteristics identified in the different landscapes.
\end{abstract}

Keywords: Geomorphology; Geosystems; Space Modeling.

\section{INTRODUÇ̃̃O}

A busca pela análise integrada do meio ambiente parte do pressuposto que, para entender as diferentes paisagens e os seus sistemas (geossistemas), se faz necessário conhecer como os diferentes componentes se relacionam entre si. Entre os principais critérios do pensamento sistêmico, temos a mudança da parte para o todo, onde os sistemas são vistos como um todo, constituídos de partes integradas cujas propriedades não podem ser analisadas isoladamente. O pensamento sistêmico tem 
como critério a contextualização, e o objeto de estudo devia estar contextualizado com o meio, "podemos dizer que todo pensamento sistêmico é pensamento ambientalista" (CAPRA, 1996, p.37). O Geossistema, conforme Bertrand (2006), é o tempo da fonte, dos componentes e mecanismos biofísicos mais ou menos antropizados que acontecem a partir do Neolítico, estando de acordo com os fenômenos espaciais e geomorfogênicos e também os aspectos biológicos.

Na aplicação de perfis e seção-tipo, podemos destacar os trabalhos de Cavalcanti (2014), onde o autor traz a seção-tipo das localidades próximas ao Xilili (município de Tupanatinga, em Pernambuco), a partir de trabalho de campo ao longo de sete quilômetros, entre altitudes de $560 \mathrm{~m}$ a $630 \mathrm{~m}$. Destacando o embasamento cristalino, a vegetação, e os solos presentes na área, em um perfil topográfico. $\mathrm{O}$ trabalho de Manosso (2008/2009), traz para um percurso de excursão de campo de $582 \mathrm{~km}$, ao longo de 7 municípios, o perfil geoecológico com precipitação anual; temperatura média anual; uso da terra: vegetação original; o perfil topográfico com os principais rios e as sedes das cidades; os solos; e as rochas.

Neste sentido faz-se necessário o uso de Geotecnologias, tornando-se uma importante ferramenta para os estudos da Geografia Física como também de todo o meio ambiente. O SIG (Sistema de Informação Geográfica) possibilita a criação e integração de diversos bancos de dados, sejam eles de carácter social, ou a respeito dos atributos físicos de determinado local (Geologia, Geomorfologia, Pedologia, Clima, etc.), que possibilita o processamento de elevado número de informações e cruzamentos de dados para diferentes análises do meio, planejamento e tomada de decisão relativas ao espaço geográfico (ROSA, 2005, p. 81), permitindo assim a criação e implementação de técnicas de representações mais fidedignas do espaço, compatível com as técnicas, escalas e dados disponíveis.

Entre as técnicas de representação das paisagens, pode-se destacar as seções-tipo, que segundo Cavalcanti (2014, p.37) serão “...qualquer representação da paisagem em um perfil topográfico denominada seção-tipo. Trata-se de um modelo que busca caracterizar as variações paisagísticas ao longo de um gradiente de relevo"..

\section{MATERIAL E MÉTODO}

Como referencial teórico-metodológico, foi levado em consideração os preceitos geossistêmicos e a metodologia adaptada por Cavalcanti (2014). Para a confecção dos perfis, fez-se uso de um conjunto de dados que reúne as informações a respeito da área de estudo (Litologia, cobertura pedológica, Geomorfologia, e cobertura vegetal). As informações referentes à Litologia e cobertura pedologia, foram adquiridas a partir do banco de dados disponível no Atlas Digital Sobre Recursos Hídricos de Sergipe, disponibilizado pela SEMARH (Secretaria de estado do meio ambiente e dos recursos hídricos) e SRH (Superintendência de recursos hídricos).

Para a construção do perfil topográfico e seções-tipo utilizou-se da imagem SRTM (Shuttle Radar Topography Mission), com resolução espacial de 30 metros, fornecidas pela NASA e NGA (National Geospatial-Intelligence Agency), disponível em $<$ http://earthexplorer.usgs.gov/>, de forma gratuita. A partir da imagem SRTM foram selecionados os transectos para a criação dos perfis, da Depressão Sertaneja, do Domo de Itabaiana, e da Planície Costeira (Figura 1).

E para as informações referentes à cobertura vegetal foram utilizados dados disponíveis no Ministério do Meio Ambiente (MMA), como também obtidos por meio da aplicação do NDVI (Índice da Vegetação por Diferença Normalizada - Normalized Difference Vegetation Index), utilizando imagem do satélite Landsat 8 (LC82150672013104LGN01), do dia 14 de abril de 2013, com uma taxa de nuvens de $0,71 \%$. 
Figura 1. Localização dos transectos para construção dos perfis.

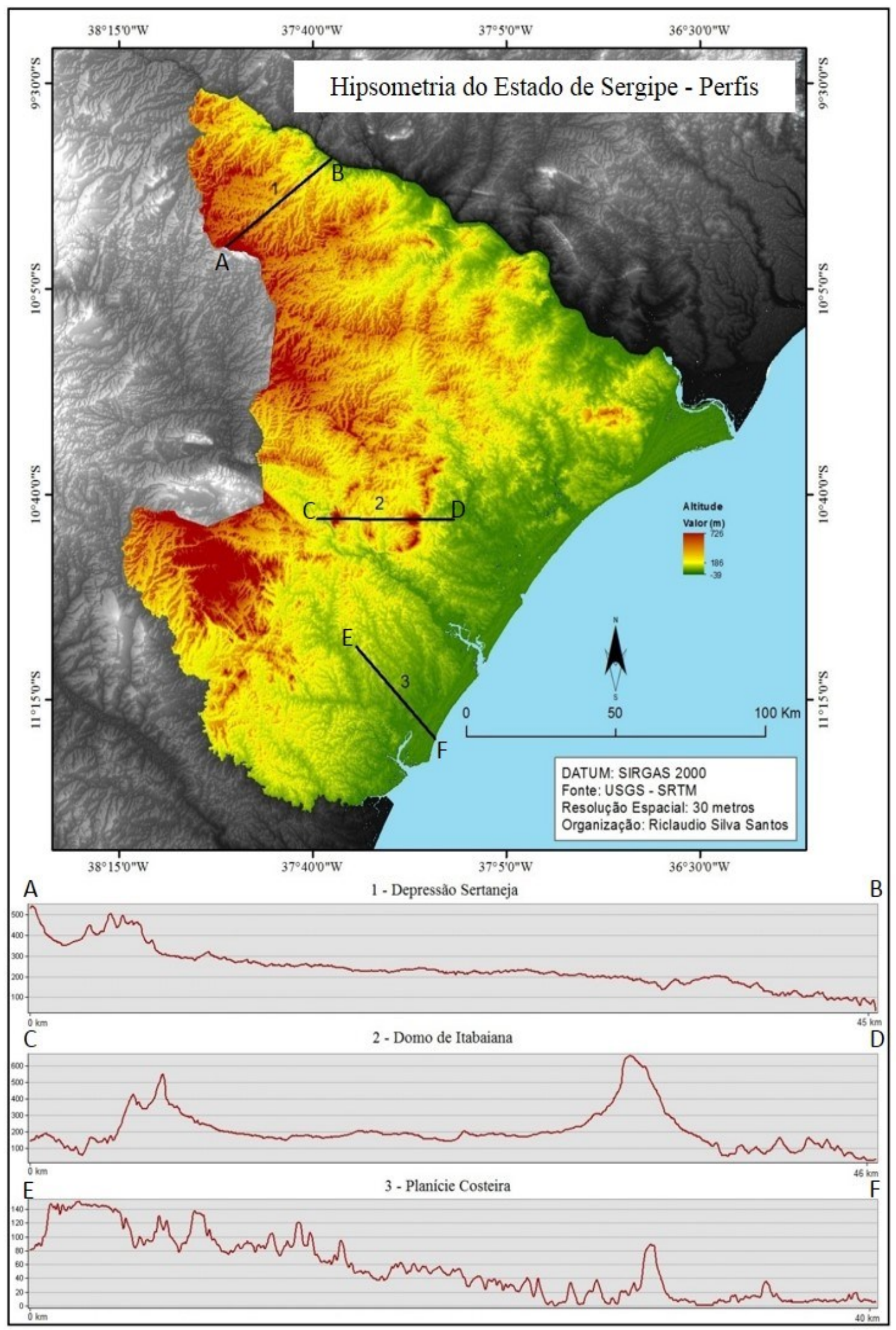




\section{RESULTADOS E DISCUSSÃO}

Após o processamento dos dados, foi possível construir os três perfis integrados representando os diferentes contextos geomorfológicos do estado de Sergipe, correspondendo à Depressão Sertaneja, o Domo de Itabaiana, e a Planície Costeira (Figuras 2, 3 e 4).

Figura 2. Perfil Depressão Sertaneja

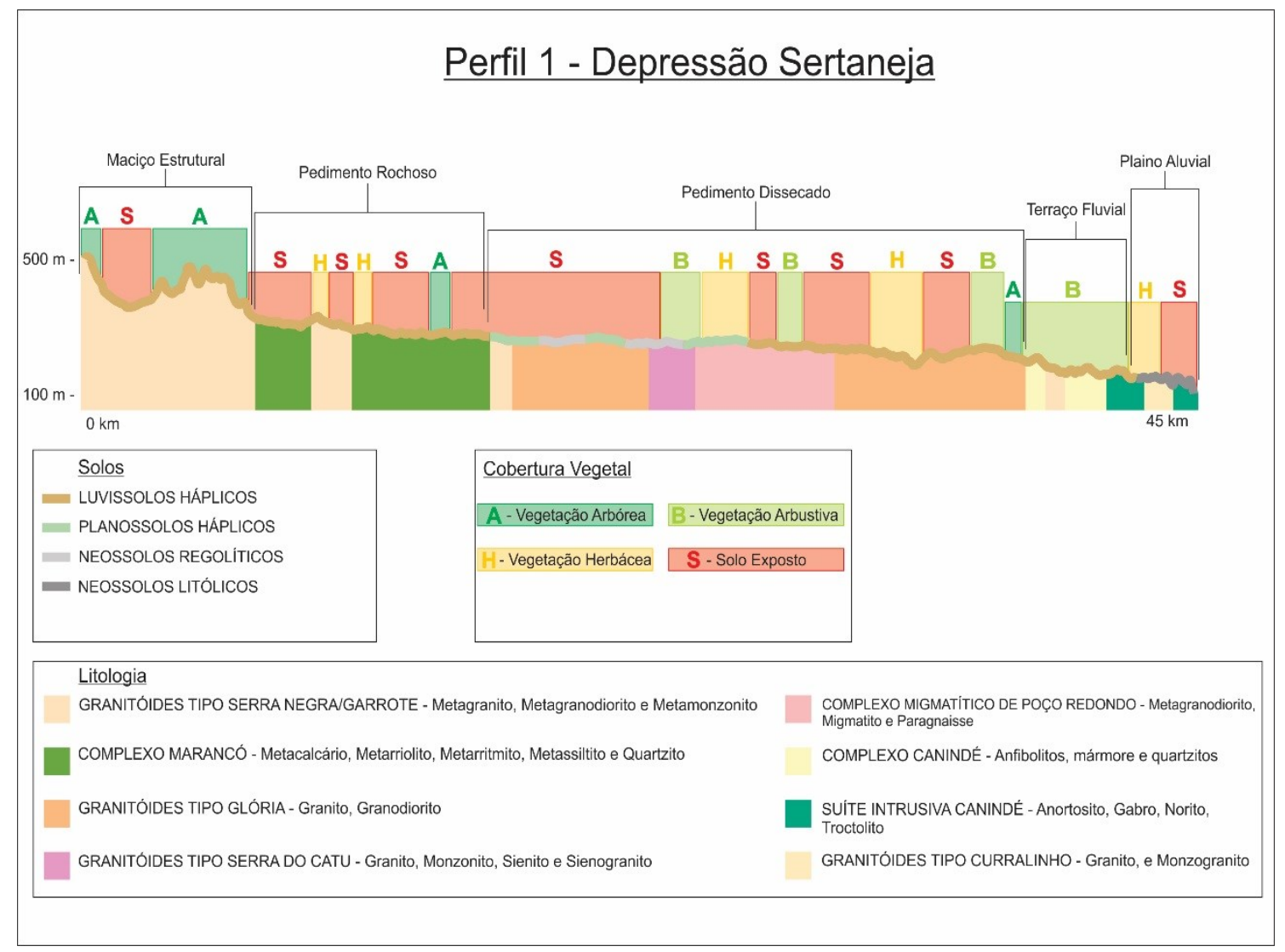

O perfil correspondente a Depressão Sertaneja abrange uma distância de $45 \mathrm{~km}$, entre as

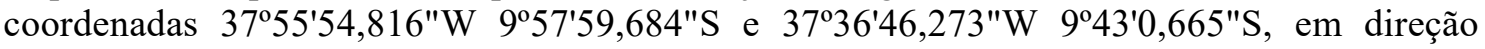
nordeste, dentro de um contexto semiárido, com precipitação média anual de $600 \mathrm{~mm}$. Com altitudes que vão de $100 \mathrm{~m}$ a 500m. Destacando-se o município de Poço Redondo.

Neste perfil encontra-se o Maciço Estrutural, com a litologia dos Granitóides tipo Serra Negra/Garrote, onde desenvolvem-se Luvissolos Háplicos, pouco desenvolvidos, que raramente ultrapassam $1 \mathrm{~m}$ de profundidade, estando presentes diversos afloramentos rochosos. $\mathrm{Na}$ área correspondente a Serra Negra a vegetação apresenta uma cobertura arbórea, com a caatinga em estado mais conservado, tendo em vista também que nesta área não há uma forte presença das pastagens para a pecuária, ou seja, uma menor interferência antrópica.

As áreas de Pedimento Rochoso e Pedimento Dissecado são marcadas por uma forte presença da pecuária de leite, e também de atividades agrícolas, principalmente o plantio do milho. A caatinga aqui apresenta-se de maneira mais degradada, a vegetação natural foi removida para a criação das pastagens, o que contribui para o surgimento de várias áreas de solo exposto. São áreas de Planossolos Háplicos e Neossolos Regolíticos, que se apresentam enquanto solos 
poucos desenvolvidos, rasos, susceptíveis à erosão. Os Inselbergs, são marcas presentes nessas paisagens, com destaque para os Granitoides tipo Glória, Granitoides tipo Serra do Catu, e o Complexo Migmatítico de Poço Redondo.

Mais próximo ao Rio São Francisco, no Terraço Fluvial e no Plaino Aluvial, a cobertura vegetal natural da caatinga apresenta um melhor estado de conservação, são áreas com maior declividade, onde desenvolvem-se Neossolos Litólicos, e justamente por serem áreas de maior declividade, que dificultam a utilização de maquinário para as atividades agropecuárias, a interferência antrópica sobre essa vegetação é menor.

Figura 3. Perfil Domo de Itabaiana.

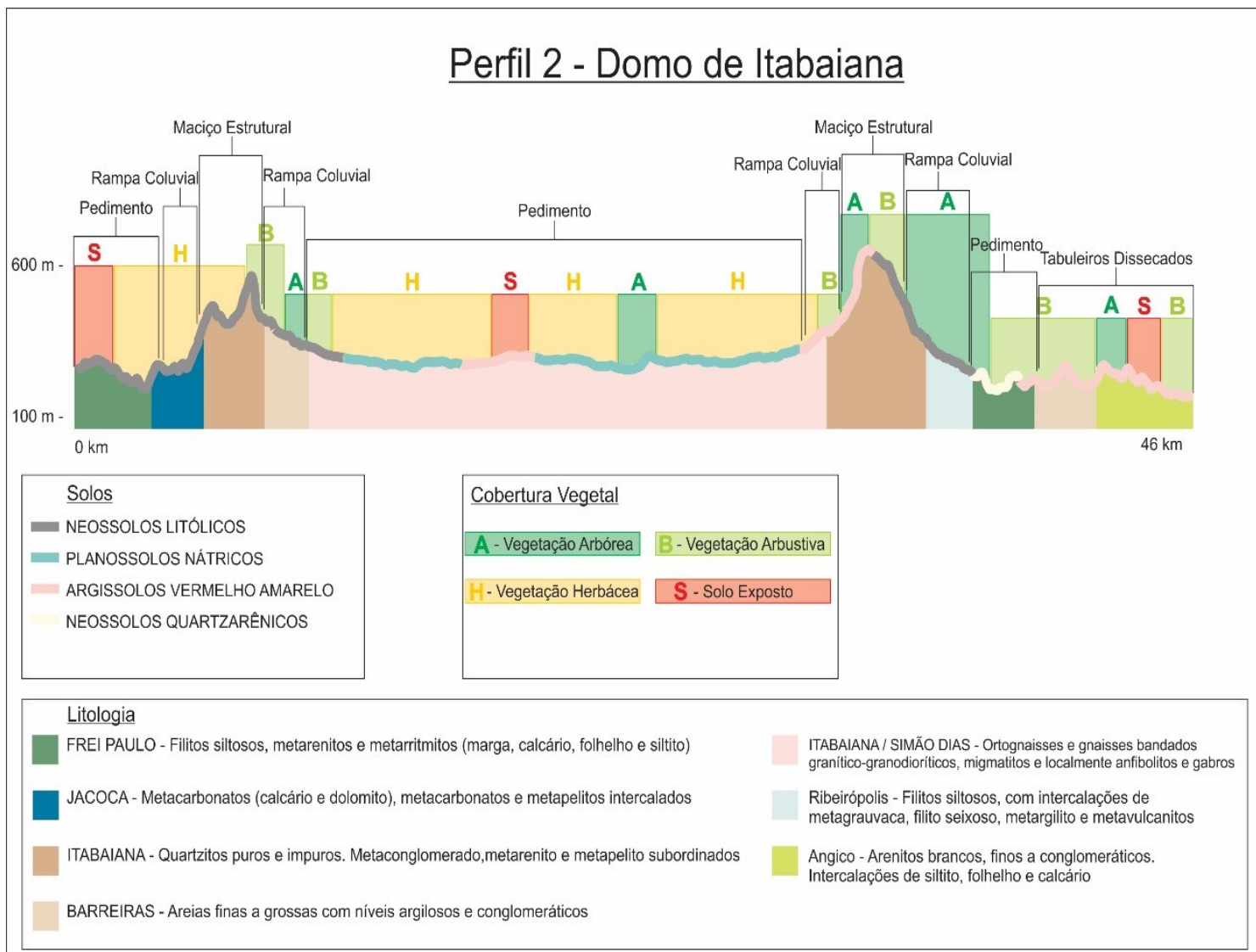

O perfil do Domo de Itabaiana corresponde a uma extensão de $46 \mathrm{~km}$, localizado entre as coordenadas $37^{\circ} 39^{\prime} 20,016^{\prime \prime} \mathrm{W} 10^{\circ} 44^{\prime} 13,009^{\prime \prime S}$ e $37^{\circ} 14 ' 33,555^{\prime \prime} \mathrm{W} 10^{\circ} 44^{\prime} 17,858^{\prime \prime} \mathrm{S}$, em direção leste, no contexto do agreste sergipano, com precipitação média anual que varia entre $1000 \mathrm{~mm}$ e $1400 \mathrm{~mm}$. Com destaque para os municípios de São Domingos, Campo do Brito, Itabaiana e Areia Branca.

Este perfil do Domo de Itabaiana apresenta dois Maciços Estruturais, a Serra da Miaba nos municípios de São Domingos e Cambo do Brito, e a Serra de Itabaiana nos municípios de Itabaiana e São Domingos, ambas com litologia da formação Itabaiana, com destaque para os quartzitos puros e impuros, que dão a característica de resistência ao intemperismo das mesmas. Nas vertentes desses maciços encontramos rampas coluviais resultantes dos processos de intemperismo. A vegetação na Serra da Miaba apresenta principalmente um porte herbáceo, tendo 
em vista que nesta área há uma menor precipitação desta área. Já na Serra de Itabaiana, encontramos uma maior cobertura vegetal de porte arbóreo, inclusive resquícios de Mata Atlântica, esta área conta também com uma maior precipitação média anual (1400mm), além da proteção às ações antrópicas fornecida pela presença do Parque Nacional Serra de Itabaiana.

Na porção central do Domo, onde se encontram as cidades de Campo do Brito e Itabaiana, a base litológica, constituída principalmente de Gnaisses, encontra-se erodida sob o pedimento. Nessa área as atividades antrópicas estão mais presentes, principalmente o cultivo de hortaliças, assim com pastagens para a pecuária. Têm uma predominância da cobertura vegetal herbácea, com exceção das áreas próximas às cidades, que apresentam manchas de solo exposto.

Cabe destacar ainda a formação das areias brancas - Neossolos Quartzarênicos, possivelmente provenientes do intemperismo realizado sobre os quartzitos da Serra de Itabaiana, ou ainda somados a processos pedogenéticos de podzolização e que dão nome ao município de Areia Branca.

Figura 4. Perfil Planície Costeira.

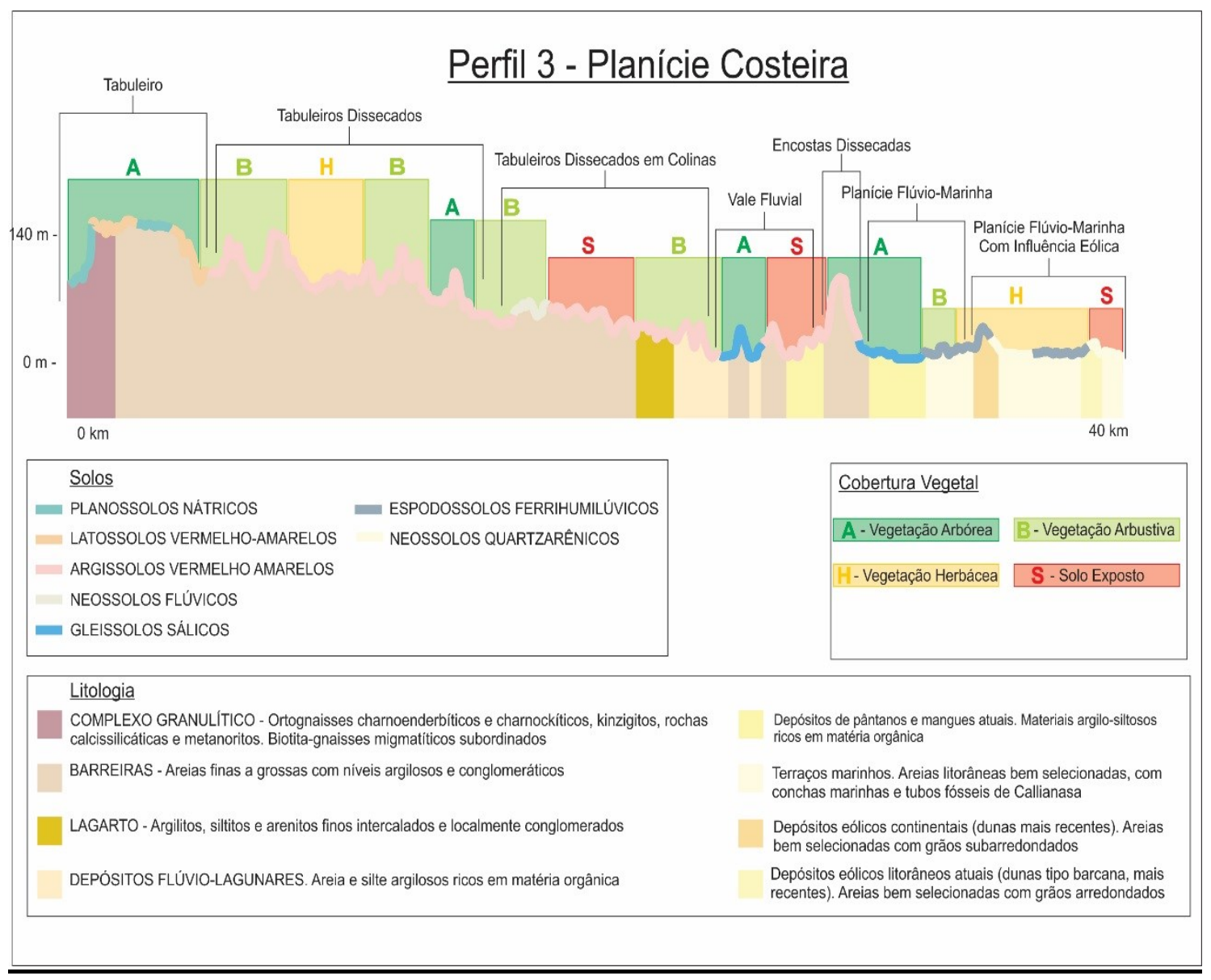

O perfil que trata da Planície Costeira possui uma extensão de $40 \mathrm{~km}$, entre as coordenadas $37^{\circ} 32^{\prime} 5,651^{\prime \prime} \mathrm{W} 11^{\circ} 6^{\prime} 5,597^{\prime \prime S}$ e $37^{\circ} 17^{\prime} 50,811^{\prime \prime W} 11^{\circ} 21^{\prime} 44,658^{\prime \prime} \mathrm{S}$, em direção sudeste. Inserido no contexto litorâneo, com precipitação média anual variando entre $1300 \mathrm{~mm}$ e $1700 \mathrm{~mm}$. Com destaque para os municípios de Salgado e Estância. 
Na porção que está mais localizada no interior do continente, estão presentes os tabuleiros mais conservados, e conforme nos dirigimos ao litoral temos os tabuleiros dissecados e os tabuleiros dissecados em colinas, com níveis de erosão que aumentam gradualmente. Nesta área temos principalmente a Formação Barreiras, formada de areias finas e grossas com níveis argilosos e conglomeráticos.

Sobre essa litologia desenvolvem-se Planossolos Nátricos nas áreas mais planas no topo dos tabuleiros, juntamente com manchas de Latossolos Vermelho-amarelos. Temos ainda a presença de Argissolos Vermelho-amarelos, e Neossolos Flúvicos próximo às margens dos rios.

A cobertura vegetal dessa região está relativamente conservada, apresentados áreas de solo exposto apenas próximo as ocupações urbanas. Por se tratar de um relevo mais íngreme, o que dificulta a aplicação das atividades agrícolas, as encostas apresentam em sua maioria uma vegetação natural arbórea, com exceção dos espaços ocupados para o plantio da cana-de-açúcar.

$\mathrm{Na}$ faixa litorânea mais propriamente dita temos uma planície flúvio-marinha, com presença de Gleissolos sálicos e Espodossolos Ferrihumilúvicos que se desenvolvem sobre os depósitos de pântanos e mangues atuais, com cobertura vegetal arbórea próxima às margens dos rios e arbustiva e herbácea sobre os terraços marinhos.

Mais próximo a linha de costa as dunas são características marcantes desta paisagem. Tanto os depósitos eólicos continentais como os depósitos eólicos litorâneos atuais (ambos recentes), com pouca cobertura herbácea desenvolvendo-se sobre os Neossolos Quartzarênicos.

\section{CONSIDERAÇÕES FINAIS}

O resultado obtido com este trabalho mostrou-se satisfatório para criar um modelo de representação das paisagens, com as características físicas do meio ambiente presentes no estado de Sergipe. Obviamente, deve-se continuar com o esforço de refinar esta metodologia a partir de novas tecnologias, e da obtenção e criação de dados de melhor qualidade.

A organização dos perfis serviu para sobrepor diferentes bases de dados dos diferentes contextos geomorfologicos sergipanos e representá-los de maneira clara, demonstrando seus aspectos físicos naturais e permitindo correlacioná-los com a interferência antrópica sobre a vegetação. A utilização do ambiente SIG permitiu cobrir uma extensa área, além do processamento dos dados. Os resultados aqui obtidos podem ser utilizados para outros estudos que busquem informações a respeito das paisagens sergipanas.

Cabe destacar ainda que o Sensoriamento Remoto e o Geoprocessamento não substitui o trabalho de campo, pois este se faz necessário para que o pesquisador tenha conhecimento empírico da sua área de estudo.

Os perfis apresentam uma variação paisagística que se inicía no semiarido, passando pelo agreste e chegando ao litoral, em diferentes contextos geomorfologicos, com litologia, pedologia e cobertura vegetal diferenciadas. A correlação entre os diferentes perfis permite perceber a mudança paisagística ao longo do estado de Sergipe, em uma "viagem" do sertão ao litoral.

\section{REFERÊNCIAS}

BERTRAND, C.; BERTRAND, G. O sistema GTP (Geossistema, Território, Paisagem) O retorno do Geográfico? (Cap. IV). In: Uma geografia transversal e de travessias: o meio ambiente através dos 
territórios e das temporalidades. Organizador: Messias Modesto dos Passos. Maringá: Ed. Massoni, 2009. 360p.

CAPRA, Fritjof. A teia da vida. São Paulo: Cultrix, 1996.

CAVALCANTI, L. C. S. Cartografia de paisagens: fundamentos. São Paulo. Oficina de Textos, 2014.

MANOSSO, Fernando Cesar. Estudo Integrado da Paisagem nas Regiões Norte, Oeste e Centro-Sul do Estado do Paraná: Relações entre a Estrutura Geoecológica e a Organização do Espaço. Bol. Geogr., Maringá, v. 26/27, n. 1, p.81-94. 2008/2009.

MAGUIRE, D.; GOODCHILD, M.F.; RHIND, D.W. (1993) Geographical Information Systems. Longman Scientific \& Technical, Vol. 1 e 2, NY.

ROSA, Roberta. Geotecnologias na Geografia Aplicada. Revista do Departamento de Geografia, 16, p.81-90. 2005.

Serviço Geológico dos Estados Unidos - USGS. Disponível em: <http://earthexplorer.usgs.gov/>. Acesso em: 20.out.2017. 